\title{
ВЛИЯНИЕ КОЛИЧЕСТВА НЕФТЯНЫХ ПЕКОВ НА ТЕРМИЧЕСКУЮ УСТОИЧИВОСТЬ И НЕКОТОРЫЕ СТРУКТУР- НЫЕ ОСОБЕННОСТИ ПОЛИКАПРОАМИДНЫХ НИТЕЙ
}

Эффективность применения асфальто-смолистых веществ нефти, в частности пеков, в качестве добавок к термопластическим полимерам показана в $\left[{ }^{1,2}\right]$. Малые добавки пеков, играя роль ингибиторов термоокислительной деструкции, придают поликапроамидным (ПКА) нитям повышенную прочность [3].

Систематических исследований по получению волокон с более высоким наполнением полимеров пеками не проводилось, в то время как такого рода волокнообразующие материалы могли бы представлять интерес в качестве сорбентов в различных технологических процессах.

В данной работе приводятся результаты исследования возможностей повышения термической устойчивости ПКА нитей путем введения в них разных количеств нефтяного пека, а также определения некоторых структурных особенностей нитей из этих композиций.

Показатели выбранного нефтяного изотропного пека: $T_{\text {пл }}-190-$ $195{ }^{\circ} \mathrm{C}$, содержание $\gamma^{-}, \beta-$ и $\alpha_{2}$-фракций $-23,8,74,9$ и $2,52 \%$ соответственно. Исследованию были подвергнуты три образца ПКА нитей с добавкой 10,28 и $70 \%$ мас. пека соответственно.

Термогравиметрический и дифференциально-термический анализы (ДТА) этих трех образцов проводили в режиме динамического нагрева со скоростью $2^{\circ}$ мин в интервале $20-300{ }^{\circ} \mathrm{C}$ и со скоростью $10^{\circ}$ мин в интервале $20-600^{\circ} \mathrm{C}$ на дериватографе системы «Paulik-Paulik-Erdey». Информацию о процессе термораспада нитей из композиции ПКА-пек получали методом ступенчатой пиролизной газовой хроматографии (СПГХ) [ [4].

Установлено, что до $300^{\circ} \mathrm{C}$ плавкость образцов и потеря массы меняются незначительно, т. е. введение нефтяного пека в ПКА не оказы-

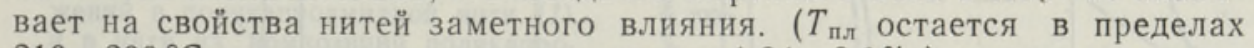
$210-200^{\circ} \mathrm{C}$, потеря массы не превышает $1,84-3,0 \%$.)

Далее, изменение термической устойчивости в зависимости от количества введенного пека оценивали по температуре интенсивной деструкции, суммарной потере массы и максимальной скорости потери массы образцов нитей при нагреве до $600{ }^{\circ} \mathrm{C}$ (табл. 1).

Потеря массы образцов модифицированных нитей начинается при температуре $290-310^{\circ} \mathrm{C}$, интенсивная потеря массы сдвигается на более высокие температуры $\left(405-425^{\circ} \mathrm{C}\right)$, сопровождается эндотермическими и экзотермическими эффектами, что свидетельствует об изменении механизма реакции под влиянием количественного содержания пека. Увеличение содержания пека до $70 \%$ мас. приводит к повышению термоустойчивости модифицированных ПКА нитей. Так, если нить, содержащая $10 \%$ мас. пека, при нагреве до $600^{\circ} \mathrm{C}$ полностью деструктирует с максимальной скоростью потери массы $15,2 \% /$ мин, то нить, содержашая $70 \%$ мас. пека. при прочих равных условиях теряет $78,4 \%$ массы со скоростьіо лишь $7,6 \% /$ мин.

На основании данных, полученных с помошью метода ДТА, можно заключить, что устойчивость композиции ПКА-пек к термодеструкции проявляется при температурах выше $300^{\circ} \mathrm{C}$. 
Влияние пека на термическую устойчивость нитей из композиции поликапроамид-пек при нагреве до $600{ }^{\circ} \mathrm{C}$ (скорость нагрева $10 \%$ мин)

\begin{tabular}{|c|c|c|c|c|c|}
\hline Образец & $\begin{array}{c}\text { Содержание } \\
\text { пека, } \\
\%\end{array}$ & $\begin{array}{c}\text { Температура } \\
\text { начала } \\
\text { деструкции, } \\
{ }^{\circ} \mathrm{C}\end{array}$ & $\begin{array}{l}\text { Температура } \\
\text { интенсивной } \\
\text { деструкции, } \\
{ }^{\circ} \mathrm{C}\end{array}$ & $\begin{array}{c}\text { Суммарная } \\
\text { потеря } \\
\text { массы, } \\
\%\end{array}$ & $\begin{array}{c}\text { Максималь- } \\
\text { ная скорость } \\
\text { потери } \\
\text { массы, } \\
\% / \text { мин }\end{array}$ \\
\hline
\end{tabular}

\section{Контрольный}

ПКА (без добавок)

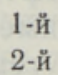

$\begin{array}{ll}\overline{10} & \overline{-} \\ 28 & 290 \\ 70 & 310\end{array}$

425
425
410
405

100,0 6,5

2 -й

310

405

100,0

15,2

90,5

14,8

78,4

Дополнительная информация о процессе термодеструкции модифицированных нитей ПКА-пек была получена методом СПГХ, который позволяет определять не только температурные интервалы термораспада, но и идентифицировать выделяющиеся летучие продукты. Основными летучими продуктами термораспада этих нитей, как и чистой поликапроамидной, тоже являются $\mathrm{CO}, \mathrm{CO}_{2}, \mathrm{NH}_{3}$ и $\mathrm{H}_{2} \mathrm{O}$.

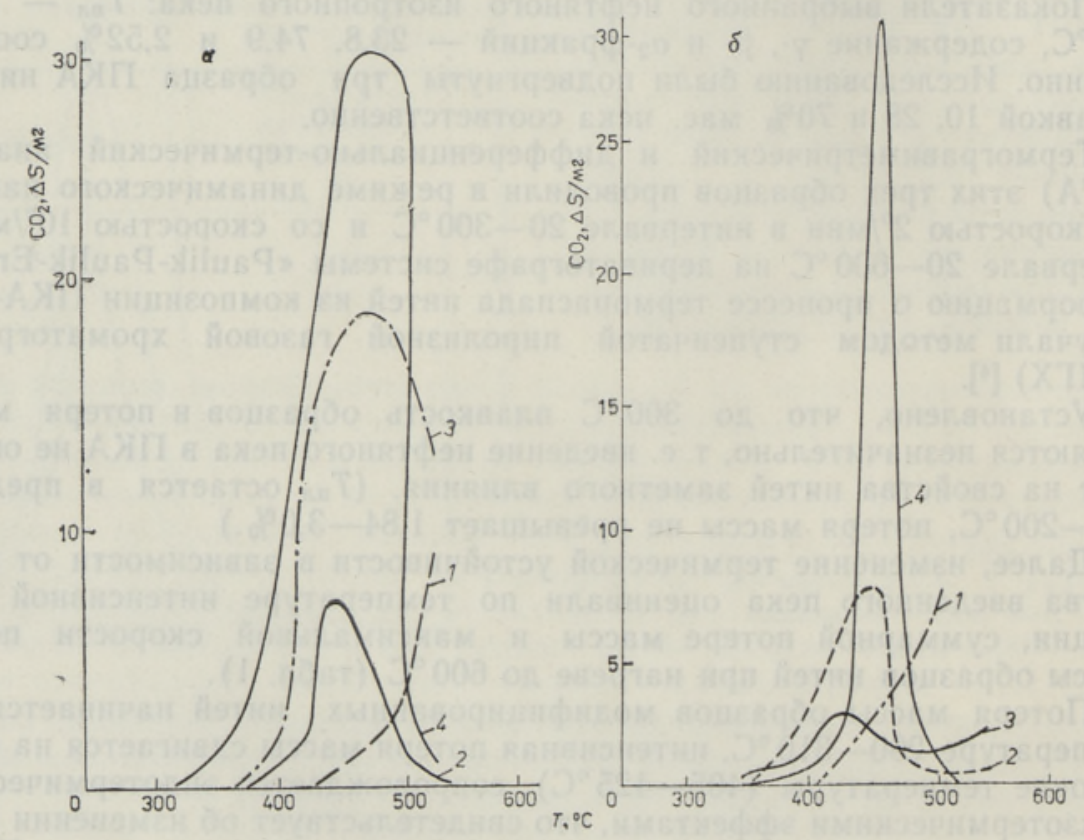

Рис. 1. Выход $\mathrm{CO}$ (а) и $\mathrm{CO}_{2}$ (б) при пиролизе нити из композиции поликапроамидпек в количестве $10(1), 28(2), 70 \%$ мас. (3) и без его добавки (4).

На рис. 1 представлены данные о выходе $\mathrm{CO}$ и $\mathrm{CO}_{2}$ при пиролизе образцов модифицированных ПКА нитей всех трех составов (для сравпения приведены аналогичные данные для чистой ПКА нити). Из исходной ПКА нити выделение летучих продуктов начинается при $T 325^{\circ} \mathrm{C}$, а из модифицированных - в области температур выше $375^{\circ} \mathrm{C}$ в зависи- 
мости от содержания введенного в ПКА пека. Выход $\mathrm{CO}$ и $\mathrm{CO}_{2}$ при пиролизе модифицированных нитей заметно снижается для всех исследуемых образцов в сравнении с чистой ПКА нитью, что указывает на ингибирующее действие пековой составляющей. Можно полагать, что введение в ПКА пековой составляющей и повышение ее содержания инициирует процесс гомолитического разрыва молекул полимера, сопровождающийся выделением $\mathrm{CO}_{2}$, оказывает ингибирующее действие на вторичные процессы деструкции ПКА, что способствует замедлению окончательной потери массы полимерной составляющей.

Представляло интерес определить также влияние пековой составляющей на некоторые свойства получаемых нитей, в частности на их структурные особенности. С этой целью были использованы методы иодной сорбции ${ }^{[5]}$ и изотермического нагрева [6], как наиболее информативные при изучении структуры композиционных нитей.

Таблица 2

Иодные числа композиционных нитей в зависимости от условий их получения

\begin{tabular}{|c|c|c|c|c|c|}
\hline Образец & $\begin{array}{c}\text { Темпера- } \\
\text { тура } \\
\text { вытяжки, } \\
{ }^{\circ} \mathrm{C}\end{array}$ & $\begin{array}{c}\text { Кратность } \\
\text { вытяжки }\end{array}$ & $\begin{array}{c}\text { Прочность } \\
\text { нити, } \\
\text { гс/текс }\end{array}$ & $\begin{array}{c}\text { Модуль } \\
\text { упругости, } \\
\text { Кг/мм² }\end{array}$ & $\begin{array}{c}\text { Иодное } \\
\text { число, } \\
\text { мг/г }\end{array}$ \\
\hline
\end{tabular}

$\begin{array}{crrrrr}\text { ПКА без добавок } & 120 & 1,5 & - & 406,9 & 1026,72 \\ \text { ПКА-пек } & - & - & 5,02 & - & 1189,90 \\ , " & 20 & 1,5 & 11,06 & - & 1165,90 \\ , & 120 & 1,5 & 8,80 & 363,4 & 1286,52\end{array}$

Рис. 2. Изменение внутренних напряжений в поликапроамидной нити (1) и в нити из композиции поликапроамид-пек (2).

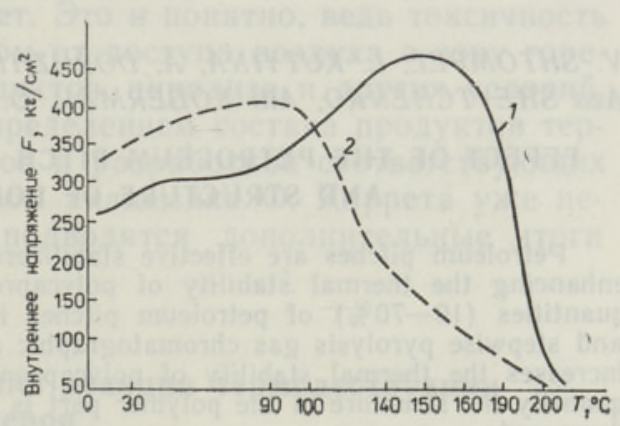

Результаты этого исследования показали (табл. 2, рис. 2), что для модифицированных нитей характерно снижение величины внутренних напряжений и смещение релаксационных областей в сторону более низких температур, что свидетельствует о несколько разориентационном влиянии пековой составляющей. Эти данные подтверждают результаты сорбционной способности этих нитей. Из табл. 2 можно видеть, что с введением в ПКА нить пековой составляющей иодное число увеличивается, что также указывает на разрыхленность структуры композиционной нити.

Полученные данные свидетельствуют о том, что исследованные полимерные композиции с высоким содержанием пеков являются термоустойчивыми, причем термоустойчивость проявляется при темпера. туре выше $300^{\circ} \mathrm{C}$. Показано также, что введение в ПКА пековых добавок повышенных концентраций приводит к некоторой дезориентации структуры полимерной составляющей. 
1. Углев В. В., Васильченко T. В. Стабилизация полимеров высокомолекулярными соединениями нефти // Пластмассы, 1987, № 6, 43 .

2. Боголюбов B. M. Стабилизация полимеров нефтяными пеками. Автореф. канд. дис. Томск, 1979.

3. Джашиашвили Т., Кряжев Ю., Киррет О., Когерман А. О термической устойчивости поликапроамида, модифицированного нефтяными пеками // Изв. АН ЭССР. Хим., 1985, 34, № 2, $150-152$.

4. Когерман A. Пиролизная газовая хроматография в исследовании термических свойств полимеров // Изв. АН ЭССР. Хим., 1984, 33, № 4, 235-242.

5. Гельфанд М. Л. Методика определения эффекта и степени стабилизации полиамид. ных волокон иодной сорбцией. Киев, 1968.

6. Загородняя C. С. Исследование устойчивости извитости нитей гофрон. Автореф. канд. дис. Киев, 1971.

Киевский филиал ВНИИВ

Поступила в редакцию

Институт химии

29/V 1989

Академии наук Эстонской ССР

V. STOMPEL, L. KUTINA, A. DOROZKIN, A. PALJUHH, L. KORNEVA, Aza SEVTSENKO, Aili KOGERMAN, O. KIRRET

\section{NAFTAPIGIDE HULGA MOJU POLUKAPROAMIIDKIUDUDE TERMILISELE PUSIVUSELE JA NENDE STRUKTUURILE}

Naftapigid on efektiivsed polümeeride stabilisaatorid. On uuritud võimalusi suurendada polükaproamiidkiudude termilist stabiilsust erinevas koguses $(10-70 \%)$ naftapigide lisamisega. DTA, TG ja astmelise pürolüüsgaasikromatograafilise analüüsi tulemused näitasid, et pigi lisand suurendab polükaproamiidi termilist vastupidavust. Pigi komponendi koguse suurenemine desorienteerib polümeerse osa struktuuri ja vähendab komposiidi tugevust.

V. SHTOMPEL, L. KUTYINA, A. DOROZHKIN, A. PALYUKH, L. KORNEVA, Aza SHEVTCHENKO, Aili KOGERMAN, O. KIRRET

\section{EFFECT OF THE PETROLEUM PITCH MASS ON THE THERMAL STABILITY AND STRUCTURE OF POLYCAPROAMIDE FIBRES}

Petroleum pitches are effective stabilizers of polymers. In this work, possibilities of enhancing the thermal stability of polycaproamide fibres by the addition of different quantities $(10-70 \%)$ of petroleum pitches have been considered. Results of DTA, TG and stepwise pyrolysis gas chromatographic analyses have shown that the pitch additive increases the thermal stability of polycaproamide. With the increasing pitch component quantity the structure of the polymer part is disturbed and the strength of the composite decreased, 